\title{
Epidermal Segments: A Useful Model System for Studying Water Transport through Fruit Surfaces
}

\author{
Martin Harz ${ }^{1}$ and Moritz Knoche ${ }^{2}$ \\ Institute for Agronomy and Crop Science, Department of Horticulture, Martin- \\ Luther-University of Halle-Wittenberg, D-06099 Halle (Saale), Germany
}

Martin J. Bukovac ${ }^{2}$

Department of Horticulture, Michigan State University, East Lansing, MI 48824-1325

\begin{abstract}
Additional index words. Capsicum annuum, Lycopersicon esculentum, Malus sylvestris, Prunus avium, Vitis vinifera, apple, pepper, sweet cherry, tomato, grape, cuticle, permeance, transpiration
\end{abstract}

\begin{abstract}
Water conductance of the cuticle of mature fruit of apple [Malus sylvestris $(\mathrm{L}$.) Mill.var. domestica (Borkh.) Mansf., 'Golden Delicious'Reinders/'Malling 9'(M.9)], sweet cherry (Prunus avium L., 'Sam'/'Alkavo'), grape (Vitis vinifera L.), pepper (Capsicum annuum L. var. annuum Fasciculatum Group, 'Jive'), and tomato (Lycopersicon esculentum Mill.) was determined using excised epidermal segments (consisting of epidermis, hypodermis, and some cell layers of parenchyma) and enzymatically isolated cuticular membranes (CM) from the same sample of fruit. Segments or CM were mounted in diffusion cells and transpiration was monitored gravimetrically. Conductance $\left(\mathrm{m} \cdot \mathrm{s}^{-1}\right)$ was calculated by dividing the flux of water per unit segment or $\mathrm{CM}$ area $\left(\mathrm{kg} \cdot \mathrm{m}^{-2} \cdot \mathrm{s}^{-1}\right)$ by the difference in water vapor concentration $\left(\mathrm{kg}^{\prime} \mathrm{m}^{-3}\right)$ across segments or $\mathrm{CM}$. Transpiration through segments and through $\mathrm{CM}$ increased with time. Conductance of segments was consistently lower than that of newly isolated CM (3 days or less). Conductance decreased with increasing time after isolation for apple, grape, or sweet cherry $\mathrm{CM}$, and for sweet cherry $\mathrm{CM}$ with increasing temperature during storage ( 5 to $33{ }^{\circ} \mathrm{C}$ for 4 days). There was no significant effect of duration of storage of $\mathrm{CM}$ on conductance in pepper or tomato fruit. Following storage of $\mathrm{CM}$ for more than $\mathbf{3 0}$ days, differences in conductance between isolated CM and excised segments decreased in apple, grape, and sweet cherry, but not in pepper or tomato. Use of metabolic inhibitors ( $1 \mathrm{mM} \mathrm{NaN}_{3}$ or $\left.0.1 \mathrm{~mm} \mathrm{CCCP}\right)$, or pretreatment of segments by freezing $\left(-19{ }^{\circ} \mathrm{C}\right.$ for 18 hours), or vacuum infiltration with water, had no effect on conductance of apple fruit segments. Our results suggest that living cells present on excised segments do not affect conductance and that epidermal segments provide a useful model system for quantifying conductance without the need for isolating the $\mathrm{CM}$. Chemical names used: sodium azide $\left(\mathrm{NaN}_{3}\right)$; carbonylcyanide m-chlorophenylhydrazone (CCCP).
\end{abstract}

Transport of water vapor through the fruit surface has often been analyzed using Fick's law of diffusion (see review by Ben-Yehoshua and Cameron, 1989):

$$
F=A_{\text {fruit }} \cdot J=A_{\text {fruit }} \cdot g \cdot \Delta C
$$

According to Fick's law, the flow rate $F\left(\mathrm{~kg} \cdot \mathrm{s}^{-1}\right)$ is a function of the product of the surface area $\left(A\right.$ in $\left.\mathrm{m}^{2}\right)$ through which transpiration occurs, and the flux of water $\left(J\right.$ in $\left.\mathrm{kg} \cdot \mathrm{m}^{-2} \cdot \mathrm{s}^{-1}\right)$ per unit surface area. $J$ is equal to the conductance ( $g$ in $\mathrm{m} \cdot \mathrm{s}^{-1}$ ) of the transpiring surface multiplied by the driving force, i.e., the gradient in water va-

Received for publication 17 June 2002. Accepted for publication 7 Dec. 2002. This research was funded in part by grants from the Deutsche Forschungsgemeinschaft (KN 402/4-1) and the Agricultural Research Service, U.S. Dept. of Agriculture (SCA 58-3607-0-129). We thank Matthias Hinz and Ruth Richter for technical assistance and Stefanie Peschel for useful discussions.

${ }^{1}$ Graduate Student.

${ }^{2}$ Professor. por concentration across the $\mathrm{CM}\left(\Delta C\right.$ in $\left.\mathrm{kg} \cdot \mathrm{m}^{-3}\right)$ (Kerstiens, 1996). Thus, by determining $F, g$ of the transpiring surface may be calculated, provided that $A$ and $\Delta C$ are known. When analyzing transpiration on a whole-fruit basis, the fruit surface area $\left(A_{\text {fruit }}\right)$ and $\Delta C$ are required, but such information may not be readily determined. For example, relationships between $A_{\text {fruit }}$ and weight, volume, or other dimensions have only been quantified for a limited number of species and cultivars (e.g., Baten and Marshall, 1943; Clayton et al., 1995; Cooke, 1970; Jones and Higgs, 1982) and fruit shape often varies markedly from simple geometric shapes (e.g., spheres, elipsoids, or cylinders). Further, $\Delta C$ is not readily measured in all species and indirect methods for estimating $\Delta C$ must often be used (e.g., Horrocks, 1964; Jones and Higgs, 1982; Maguire et al., 2000; Shirazi and Cameron, 1993). Errors in estimating $A_{\text {fruit }}$ or $\Delta C$ may lead to an erroneous estimate of $g$ (Jones and Higgs, 1982). Finally, $g$ obtained on a wholefruit basis represents a mean value for the entire fruit surface (Jones and Higgs, 1982), but $g$ may vary with position on or surface characteristics of the fruit, e.g., proximal regions with calyx (apple fruit) or stylar scar (sweet cherry) vs. distal regions with stem cavity (apple, sweet cherry) or stem scar (tomato) (Cameron and Yang, 1982; Jones and Higgs, 1982; Knoche et al., 2000) or russeted vs. non-russeted areas of the apple fruit (Jones and Higgs, 1982). These observations demonstrate that, for certain questions, analysis of transpiration on a whole-fruit basis may have limitations.

The rate-limiting step in water transport is penetration of the cuticular membrane (CM), which covers all organs of primary origin in terrestrial plants (Esau, 1969). Hence, in vitro systems using enzymatically isolated CM mounted in diffusion cells have been employed to study water transport under defined conditions. Such systems are useful because: 1) $A$ may be standardized by mounting CM in defined diffusion cell systems, thereby restricting water movement to a given area; 2) $\Delta C$ may be standardized or experimentally varied, even beyond the range occurring in vivo; 3 ) experimental conditions may be precisely controlled in an essentially physical system; and 4) measurements may be made on specific regions of the fruit surface. Despite these advantages, isolated CM have limitations. First, studies are limited to species and organs where the CM can be isolated and have sufficient strength to be manipulated for mounting in diffusion cells. Often, CMisolated from stomatous surfaces tear when separating from epidermal cells. Second, artifacts cannot be completely excluded during the isolation process. For example, CM may sorb materials (mostly lipophilic) released on isolation, and effects of these materials on water vapor permeability are not known (Schönherr and Riederer, 1986). Also, mechanical stress, i.e., flexing and bending, may occur during isolation, and the effects of such stress factors on permeability have not been quantified.

We recently adopted a system that employed epidermal segments excised from fruit and mounted in diffusion cells (Knoche et al., 2000, 2001). This system proved useful for studying water transport through sweet cherry fruit surfaces by providing a level of control similar to that of systems using isolated CM, but avoiding some of their potential disadvantages. The objective of this study was to determine if conductance values obtained when using segments excised from the surface of fruit of selected species are similar to their isolated CM. We selected apple, grape, pepper, sweet cherry, and tomato fruit, since these fruit CM can be readily isolated and mounted in diffusion cells. Further, uncontrolled water uptake may result in cracking in a number of these fruits.

\section{Materials and Methods}

Mature apple fruit were obtained from the Horticultural Research Station Kühnfeld (Halle, Germany), mature sweet cherry fruit from a commercial orchard near Eisleben, Germany, and greenhouse-grown, mature green fruit of bell pepper from the Horticultural Experiment Station LVG Straelen (Straelen, Germany). To- 
matoes and grapes were purchased locally. Fruit were held at $5^{\circ} \mathrm{C}, 80 \%$ relative humidity $(\mathrm{RH})$ (apple and grape), at $1 \pm 1{ }^{\circ} \mathrm{C}, 95 \% \mathrm{RH}$ (sweet cherry) or at $9 \pm 1{ }^{\circ} \mathrm{C}, 85 \% \mathrm{RH}$ (pepper and tomato) for no longer than 1 week except for apple (6 weeks). A sample of fruit was selected for uniformity of development and freedom from visual defects and used as a source of epidermal segments and of isolated CM. Segments $\approx 2 \mathrm{~mm}$ thick, consisting of epidermis, hypodermis and some adhering cell layers of parenchyma, were excised from the equatorial regions of fruit of all species by cork borer (15.3-mm diameter) and detached using a razor blade. Surface moisture adhering to the cut surface was removed by blotting with tissue paper (Kimwipes ${ }^{\circledR}$ Lite 200; Kimberly-Clark Corp., Roswell, Ga.). The CM were isolated enzymatically (Orgell, 1955; Yamada et al., 1964). Segments were incubated in a buffered (50 mM citrate, $\mathrm{pH} 4.0$ ) solution containing pectinase $\left(90 \mathrm{~mL} \cdot \mathrm{L}^{-1}\right.$ panzym extra; Novo Nordisk Ferment Ltd., Dittingen, Switzerland) and $\mathrm{NaN}_{3}(1 \mathrm{~mm})$ to prevent microbial growth. The enzyme solution was refreshed repeatedly until CM separated from the tissue (up to 4 weeks after excision). Following isolation, $\mathrm{CM}$ were extensively desorbed to remove material that may have been sorbed during the isolation process, subsequently air-dried and stored at ambient temperature, unless otherwise specified, until used. Since $\mathrm{CM}$ of sweet cherry fruit were very fragile, isolated $\mathrm{CM}$ were transferred from water onto Teflon ${ }^{\circledR}$-sheets $\left(\approx 2.5 \times 2.5 \mathrm{~cm}^{2}\right)$ using a camel's hair brush, air-dried at room temperature, and stored on these sheets until needed. For removal from sheets, CM were gently touched with the brush and immediately transferred from the sheet onto the diffusion cells.

Segments and isolated CM were mounted in stainless steel diffusion cells, similar to those described by Geyer and Schönherr (1988), using a high vacuum grease (Hochvakuumfett schwer; Wacker-Chemie $\mathrm{GmbH}$, München, Germany). Unless otherwise specified, 0.5 $\mathrm{mL}$ of deionized water was pipetted into the donor compartment and the diffusion cell was tape-sealed (tesa Film ${ }^{\circledR}$; Tesa-Werke Offenburg GmbH, Offenburg, Germany). Based on earlier studies, water loss from tape-sealed diffusion cells was insignificant relative to water transpired through segments (Knoche et al., 2000). Diffusion cells were placed upside down over dry silica in polyethylene boxes such that outer surfaces of segments and isolated CM faced the silica (see Fig.1A in Knoche et al., 2000). The distance between CM and the silica was $\approx 2 \mathrm{~mm}$ and hence, conductance of the air layer between CM and the silica was two orders of magnitude larger than CM conductance. Because of difficulty in identifying the outer surface of isolated sweet cherry $\mathrm{CM}$, the orientation may have varied. Temperature during diffusion was maintained at $22 \pm 1^{\circ} \mathrm{C}$ except for two studies on tomato that were performed at $25 \pm 1^{\circ} \mathrm{C}$. Water transpired was monitored by weighing the diffusion cells at designated time intervals $( \pm 10 \mu \mathrm{g}$, model RCP $210 \mathrm{P}$; Sartorius AG, Göttingen, Germany) the first weighing was performed within $1 \mathrm{~h}$ after filling the donor compartment. Total water transpired during a given experiment was $<25 \mathrm{mg}$, equivalent to $5 \%$ of total water in the donor compartment.

The effect of metabolic inhibitors on transpiration of apple fruit segments was measured by performing sequential treatments on an individual segment basis. Initial flow rates over 0 to $64 \mathrm{~h}$ were established using only water as the donor. At $64 \mathrm{~h}$ after initiation of the experiment, water was replaced with solutions containing $1 \mathrm{~mm}$ sodium azide $\left(\mathrm{NaN}_{3}\right.$; Merck KG, Darmstadt, Germany), 0.1 mm carbonylcyanide m-chlorophenylhydrazone (CCCP; Sigma-Aldrich Chemie GmbH, Deisenhofen, Germany) or water (control). The experiment was continued for an additional $64 \mathrm{~h}$ to establish flow rates on the same segments in the presence of inhibitors ( $\mathrm{n}=10$ segments).

Effects of freezing/thawing or vacuum infiltration on water conductance of excised apple fruit segments were determined by positioning segments on moist filter paper at $-19{ }^{\circ} \mathrm{C}$ for $18 \mathrm{~h}$, then thawing. For vacuum infiltration, segments were placed in deionized water and pressure was reduced repeatedly until all air was replaced with deionized water. Non-treated segments served as control. Following pretreatment, segments were mounted on diffusion cells as described above $(\mathrm{n}=19$ segments)

To estimate conductance of the tissue ( $g_{\text {tis- }}$ sue) associated with the $\mathrm{CM}$ in the excised fruit segments, transpiration was studied through discs of apple cortical tissue (mean thickness $1.25 \pm 0.065 \mathrm{~mm}$ ) excised from the equatorial portion of the fruit. To avoid artifacts due to water flow driven by hydrostatic pressure through the intercellular spaces of fruit tissue into the silica when incubating diffusion cells upside down, diffusion cells were incubated in an upright position under identical conditions as described above ( $\mathrm{n}=15$ segments).

The effect of storage duration of isolated, air-dried CM at ambient temperature was investigated using $\mathrm{CM}$ from apple and sweet cherry fruit stored for $1,8,30$, and $86 \mathrm{~d}$ (apple) or $1,2,4,8,16,31,53$, and $63 \mathrm{~d}$ (sweet cherry, $\mathrm{CM}$ stored on Teflon sheets). Further, for sweet cherry $\mathrm{CM}$ the effect of temperature during storage of isolated air-dried CM (on Teflon sheets) was established following a 4-d storage period at $5,10,18$, and $33^{\circ} \mathrm{C}\left(\right.$ all $\left.\pm 1^{\circ} \mathrm{C}\right)$. Water vapor pressure deficit was maintained constant at $0.5 \mathrm{KPa}$ by storing $\mathrm{CM}$ above saturated solutions of $\mathrm{CaCl}_{2}$ at $5{ }^{\circ} \mathrm{C}, \mathrm{Ca}\left(\mathrm{NO}_{3}\right)_{2}$ at $10{ }^{\circ} \mathrm{C}$, $\mathrm{NaCl}$ at $18{ }^{\circ} \mathrm{C}$, and $\mathrm{KNO}_{3}$ at $33^{\circ} \mathrm{C}$ (data for water vapor pressures obtained from Wexler, 1995). Following storage treatments, CMs were removed from Teflon sheets and mounted in diffusion cells as described above.

Flow rates $(F)$ were determined on an individual segment or CM basis. Briefly, a regression line was fitted through the linear portion of a plot of weight loss of diffusion cells vs. time. The minimum number of data points was four, and coefficients of determination $\left(r^{2}\right)$ were usually $>0.980$. $F$ corresponded to the slope of the linear regression line. Fluxes $(J)$ were calculated by dividing $F$ by the area of the orifice of the diffusion cell $\left(A_{\text {orifice }}=38.5 \mathrm{~mm}^{2}\right)$. Conductance $(g)$ was calculated by dividing $J$ by the difference in water vapor concentration between donor and receiver compartments $(\Delta C)$. Since the water vapor concentration over dry silica is nearly zero (Geyer and Schönherr, 1988), the driving force for diffusion equaled the water vapor concentration in the donor compartment, i.e., the water vapor concentration at saturation at the respective temperature. The $g$-values thus obtained are in the units $\mathrm{m} \cdot \mathrm{s}^{-1}$. Conversion factors to calculate conductance values in other units may be obtained from Banks et al. (1995).

Data for $g$ followed a log normal distribution (Baur, 1997) and, hence, log-transformed data were subjected to analysis of variance where appropriate (Proc GLM; SAS program package version 6.12; SAS Institute, Cary, N.C.). Data in the figures and table are presented as back-transformed means of log-transformed

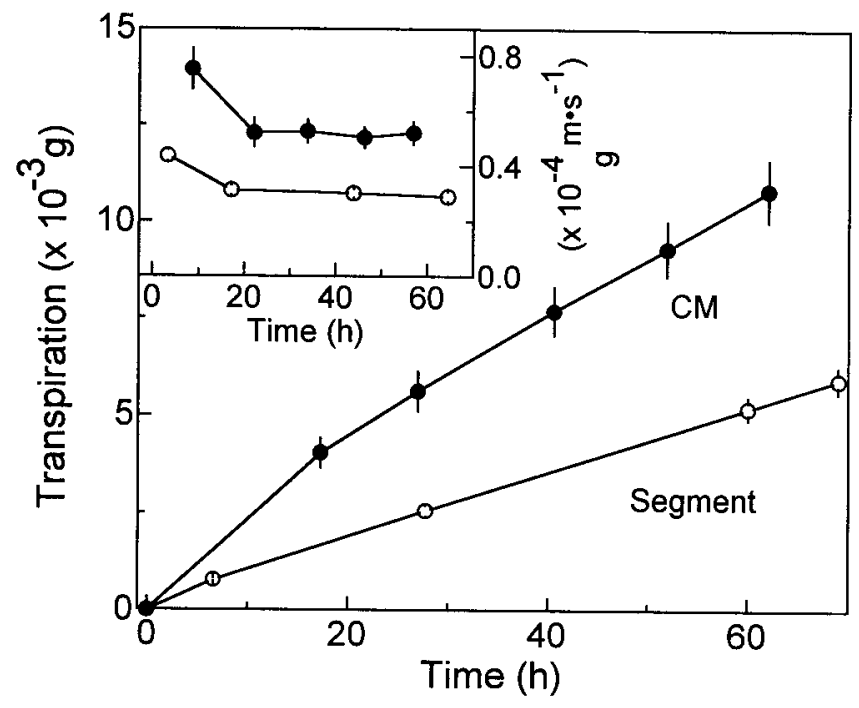

Fig. 1. Time course of transpiration through excised epidermal segments and isolated cuticular membranes (CM) from the same sample of apple fruit. CM were held for $1 \mathrm{~d}$ after isolation before initiating the experiment. Inset: Time course of water conductance $(g)$. 
data; vertical bars in figures represent standard error bars.

\section{Results and Discussion}

The amount of water transpired through segments and isolated CM of apple fruit increased with time (see example for apple in Fig. 1). In some experiments, initial transpiration, and hence $g$, was somewhat higher at the first sampling interval, but then decreased and remained constant thereafter(Fig. 1, inset). The $g_{\text {segment }}$ was lowest for apple and tomato fruit and increased in the order grape, sweet cherry, and pepper (Table 1). Conductance for the segments was consistently lower than for isolated cuticle from the same fruits when used within 1 to $3 \mathrm{~d}$ of isolation (Table 1). It may be argued that the lower $g_{\text {segment }}$ was an effect of the tissue associated with the CM. However, several lines of evidence suggest that transpiration through segments was a physical process primarily limited by the CM. First, pre-treating apple fruit segments by freezing $\left(g_{\text {segment }}=0.36 \pm 0.03 \times 10^{-4} \mathrm{~m} \cdot \mathrm{s}^{-1}\right)$ or vacuum infiltration $\left(g_{\text {segmen }}=0.44 \pm 0.07 \times 10^{-4} \mathrm{~m} \cdot \mathrm{s}^{-1}\right)$ had no effect on $g_{\text {segment }}$ (control: $g_{\text {segmen }}=0.39 \pm$ $0.03 \times 10^{-4} \mathrm{~m} \cdot \mathrm{s}^{-1}$ ). Second, there was no effect of metabolic inhibitors on $g_{\text {segment }}$ in apple. Ratio of conductance after $\left(g_{\text {after }}\right)$ to before treatment $\left(g_{\text {before }}\right)$ did not significantly differ among control $\left(g_{\text {after }} / g_{\text {befor }}=1.01 \pm 0.06\right), \mathrm{NaN}_{3}\left(g_{\text {after }} / g_{\text {before }}\right.$ $=0.91 \pm 0.04)$, and CCCP $\left(g_{\text {after }} / g_{\text {before }}=1.04\right.$ $\pm 0.05)$. Third, conductance of excised apple cortical segments averaged $g_{\text {tissue }}=48.0 \pm 0.2 \times$ $10^{-4} \mathrm{~m} \cdot \mathrm{s}^{-1}$, and thus was larger by two orders of magnitude than conductance of segments with CM. Furthermore, in an earlier study on sweet cherry we found no effect of tissue thickness on $g_{\text {segment }}$ as would be expected if the tissue was not a substantial barrier to conductance (Knoche et al., 2000). Hence, the CM must account for the apparent difference between $g_{\text {segment }}$ and $g_{\mathrm{CM}}$.

Geyer and Schönherr (1990) observed a marked decrease in permeability during storage of air-dried CM isolated from Citrus aurantium L. leaves, and similar findings have been reported for leaf CM of other species (Kirsch et al., 1997). Hence, we investigated whether the difference between $g_{\text {segment }}$ and $g_{\mathrm{CM}}$ was related to storage of the isolated CM. Indeed, the $g_{\mathrm{CM}}$ of apple and sweet cherry fruit decreased exponentially with increasing storage time after isolation, and approached an equilibrium $g_{\mathrm{CM}}$ in $\approx 30 \mathrm{~d}$ (Fig. 2). The $g_{\mathrm{CM}}$ of sweet cherry fruit $\mathrm{CM}$ after $4 \mathrm{~d}$ of storage was negatively related to storage temperature (Fig. 2, inset). Similarly, the $g_{\mathrm{CM}}$ for grape, but not for tomato or pepper, decreased during storage (Table 1). Geyer and Schönherr (1990) attributed the decrease of CM permeability during storage to an increase in the fraction of crystalline cuticular wax which is thought to be less permeable to water and organic molecules than the amorphous wax component within the CM (Baur, 1998). The absence of a storage effect on the $g_{\mathrm{CM}}$ of tomato and pepper implied that: 1) there may be less crystalline wax or 2) there is no crystallization taking place in the waxes of these species.

Across species the relationship between $g_{\mathrm{CM}}$
Table 1. Water conductance of excised epidermal segments $\left(g_{\text {segment }}\right)$ and isolated cuticular membranes $\left(g_{\mathrm{CM}}\right)$ from fruit of selected species. Data represent back-transformed means of log-transformed $g_{\text {segment }}$ and $g_{\mathrm{CM}}{ }^{2}$

\begin{tabular}{|c|c|c|c|}
\hline \multirow[b]{2}{*}{ Species } & \multirow[b]{2}{*}{$g_{\text {segment }}\left(\times 10^{-4} \mathrm{~m} \cdot \mathrm{s}^{-1}\right)$} & \multicolumn{2}{|c|}{$g_{\mathrm{CM}}\left(\times 10^{-4} \mathrm{~m} \cdot \mathrm{s}^{-1}\right)^{\mathrm{y}}$} \\
\hline & & $1-3 \mathrm{~d}$ storage & $>30 \mathrm{~d}$ storage \\
\hline Apple & $0.34 \mathrm{~b}$ & $0.52 \mathrm{a}$ & $0.23 \mathrm{c}$ \\
\hline Grape & $0.72 \mathrm{~b}$ & $0.95 \mathrm{a}$ & $0.76 \mathrm{~b}$ \\
\hline Pepper & $1.83 \mathrm{~b}$ & $2.47 \mathrm{a}$ & $2.74 \mathrm{a}$ \\
\hline Sweet cherry & $1.14 c^{x}$ & $4.51 \mathrm{a}$ & $1.91 \mathrm{~b}$ \\
\hline Tomato: source 1 & $0.29 \mathrm{~b}$ & $0.42 \mathrm{a}$ & $0.43 \mathrm{a}$ \\
\hline source 2 & $0.36 \mathrm{~b}$ & $0.77 \mathrm{a}$ & $0.67 \mathrm{a}$ \\
\hline
\end{tabular}

${ }^{2}$ Numbers of replication were (systems: epidermal segment/CM<3d/CM $>30 \mathrm{~d}$ ): apple $147 /$ 49/99, grape 50/47/51, pepper 50/50/51, sweet cherry 357/53/104, tomato source $148 / 49 / 38$, tomato source $245 / 45 / 45$. Means within species and source followed by the same letter are not significantly different, Tukey's studentized range test at $P=0.05$.

${ }^{\mathrm{y}}$ Isolated cuticles were air-dried and stored at $20 \pm 2{ }^{\circ} \mathrm{C}$ for the time periods indicated prior to initiation of the experiment.

${ }^{x}$ Data for $g_{\text {segment }}$ from Knoche et al. (2000).

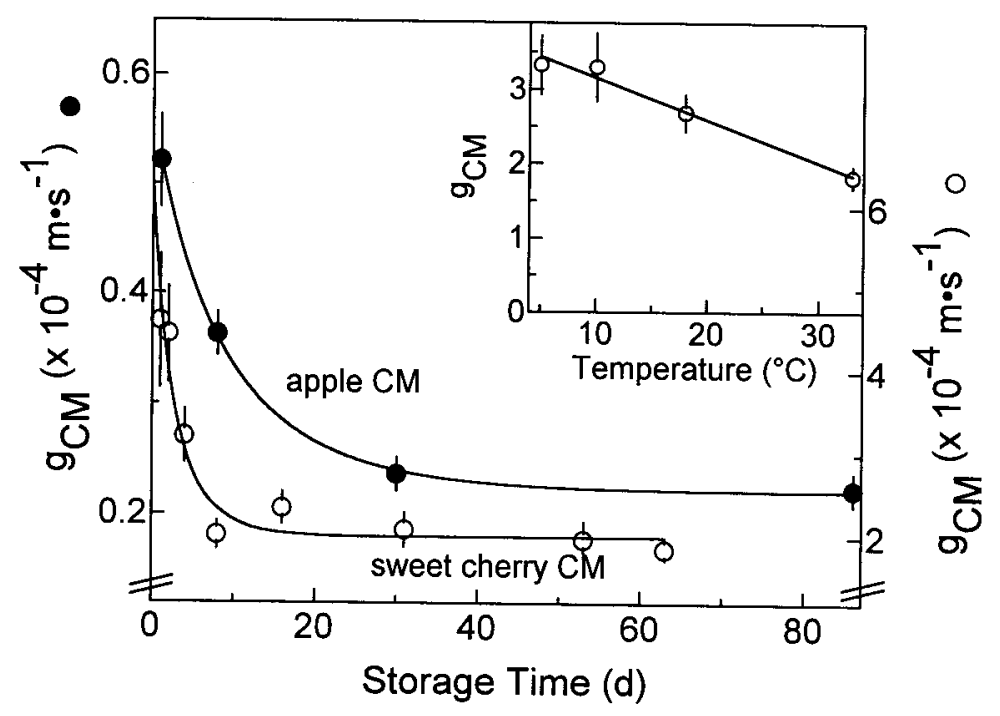

Fig. 2. Effect of storage time of isolated apple and sweet cherry fruit $\mathrm{CM}$ on water conductance $\left(g_{\mathrm{CM}}\right)$. Inset: Effect of temperature at constant water vapor pressure deficit during a 4-d storage period on water conductance of sweet cherry fruit $\mathrm{CM}$.

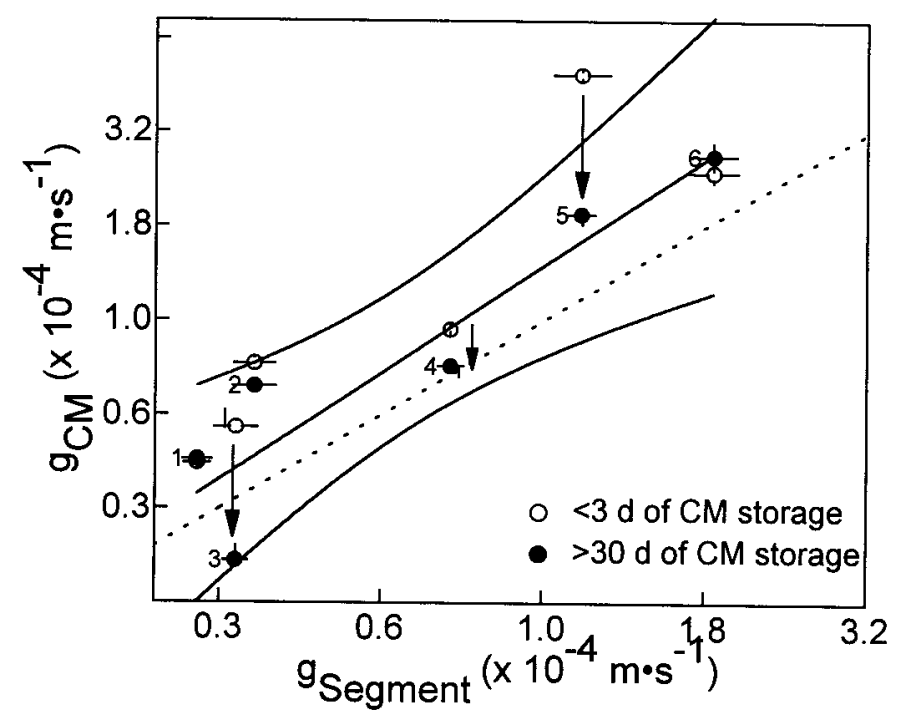

Fig. 3. A comparison between water conductance of excised segments $\left(g_{\text {segment }}\right)$ and $\mathrm{CM}\left(g_{\mathrm{CM}}\right)$ isolated from the same sample of fruit of tomato $(1,2)$, apple (3), grape (4), sweet cherry (5), and pepper (6). Axes on $\log$ scale. Data for $g_{\text {segment }}$ of sweet cherry taken from Knoche et al. (2000). Dashed line indicates 1: 1 relationship; curved lines upper and lower $95 \%$ confidence limits; arrows the decrease in $g_{\mathrm{CM}}$ during storage of CM. For regression equation see text. 
and $g_{\text {segment }}$ was significant and highest coefficients of determination were obtained when using $g_{\mathrm{CM}}$ data from $\mathrm{CM}$ that had been stored for a sufficiently long period of time:

$$
\begin{aligned}
\log g_{\mathrm{CM}}\left(\mathrm{m} \cdot \mathrm{s}^{-1}\right) \\
\quad=1.13( \pm 0.24) \times \log g_{\text {segment }}\left(\mathrm{m} \cdot \mathrm{s}^{-1}\right) \\
\quad+0.68( \pm 1.00), r^{2}=0.852^{* * *}(\text { Fig. 3) }
\end{aligned}
$$

The Y-axis intercept was not significantly different from zero $(P=0.536)$, and forcing the regression line through the origin resulted in a slope of $0.97\left( \pm 0.02 ; r^{2}=0.999^{* * *}\right)$. These data demonstrate that water conductance of epidermal segments is determined by, and closely related to, conductance of isolated $\mathrm{CM}$ that have been stored for sufficiently long periods of time. Compared to isolated CM, epidermal segments provide some experimental advantages in that they: 1) are readily obtained by excision; 2) may be prepared from species having $\mathrm{CM}$ that cannot be isolated intact; 3 ) are easier to handle during experimentation; and 4) closely reflect the characteristics of the $\mathrm{CM}$ associated with the epidermis in vivo. Potential artifacts that may be associated with CM isolation (Schönherr and Riederer, 1986) are avoided. Some differences remained between $g_{\text {segment }}$ and $g_{\mathrm{CM}}$ even after extended storage (e.g., apple, pepper, sweet cherry, tomato); the basis for these deviations is not known. Potential reasons include: 1) a shorter pathway for transport in $\mathrm{CM}$ than in epidermal segments that have been isolated from stomatous surfaces (e.g., sweet cherry fruit); 2) a potential contribution of the cell wall of epidermal cell layer(s) that may have a lower intercellular volume than the parenchyma discs investigated in our study; 3) difficulties and stress imposed unintentionally when preparing fragile $\mathrm{CMs}$ (sweet cherry fruit); and 4) errors related to the surface curvature of fruit that may result in not perfectly flat CM.

The focus of this study was water transport in transpiration, but we would expect the epidermal segment system to be equally effective for studying uptake of water or, possibly, agrochemicals applied to the surface of fruit.

\section{Literature Cited}

Banks, N.H., D.J. Cleland, A.C. Cameron, R.M. Beaudry, and A.A. Kader. 1995. Proposal for a rationalized system of units for postharvest research in gas exchange. HortScience 30: 1129-1131.

Baten, W.D. and R.E. Marshall. 1943. Some methods for approximate prediction of surface area of fruits. J. Agr. Res. 66:357-373.

Baur, P. 1997. Lognormal distribution of water permeability and organic solute mobility in plant cuticles. Plant Cell Environ. 20:167-177.

Baur, P. 1998. Mechanistic aspects of foliar penetration of agrochemicals and the effect of adjuvants. Recent Res. Dev. Agr. Food Chem. 2:809-837.

Ben-Yehoshua, S. and A.C. Cameron. 1989. Exchange determination of water vapor, carbon dioxide, oxygen, ethylene, and other gases of fruits and vegetables, p. 177-193. In: H.F. Linskens and J.F. Jackson (eds.). Gases in plant and microbial cells. Springer-Verlag, Berlin.

Cameron,A.C. and S.F. Yang. 1982. Asimple method for the determination of resistance to gas diffusion in plant organs. Plant Physiol. 70:21-23.

Clayton, M., N.D. Amos, N.H. Banks, and R.H. Morton. 1995. Estimation of apple fruit surface area. N.Z. J. Crop Hort. Sci. 23:345-349.

Cooke, J.R. 1970. Mathematical determination of surface area and volume for developing apple, lemon and peach fruits. Annu. Mtg. Amer. Soc. Agr. Eng. Paper 70-338:1-36.

Esau, K. 1969. Pflanzenanatomie. Gustav Fischer Verlag, Stuttgart, Germany.

Geyer, U. and J. Schönherr. 1988. In vitro test for effects of surfactants and formulations on permeability of plant cuticles, p. 22-33. In: B. Cross and H.B. Scher (eds.). Pesticide formulations: Innovations and developments. Amer. Chem. Soc., Washington, D.C.

Geyer, U. and J. Schönherr. 1990. The effect of the environment on the permeability and composition of citrus leaf cuticles. I. Water permeability of isolated cuticular membranes. Planta 180:147-153.

Horrocks, R.L. 1964. Wax and the water vapour permeability of apple cuticle. Nature 203:547.

Jones, H.G. and K.H. Higgs. 1982. Surface conductance and water balance of developing apple (Malus pumila Mill.) fruits. J. Expt. Bot. 33:67-77.

Kerstiens, G. 1996. Cuticular water permeability and its physiological significance. J. Expt. Bot. 47:1813-1832.

Kirsch, T., F. Kaffarnik, M. Riederer, and L. Schreiber. 1997. Cuticular permeability of the three tree species Prunus laurocerasus L., Ginkgo biloba L. and Juglans regia L.: Comparative investigation of the transport properties of intact leaves, isolated cuticles and reconstituted cuticular waxes. J. Expt. Bot. 48:1035-1045.

Knoche, M., St. Peschel, M. Hinz, and M.J. Bukovac. 2000. Studies on water transport through the sweet cherry fruit surface: Characterizing conductance of the cuticular membrane using pericarp segments. Planta 212:127-135.

Knoche, M., St. Peschel, M. Hinz, and M.J. Bukovac. 2001. Studies on water transport through the sweet cherry fruit surface: II. Effect of fruit development on conductance. Planta 213: 927-936.

Maguire, K.M., N.H. Banks, A. Lang, and I.L. Gordon. 2000. Harvest date, cultivar, orchard and tree effects on water vapor permeance in apples. J. Amer. Soc. Hort. Sci. 125:100-104.

Orgell, W.H. 1955. The isolation of plant cuticle with pectic enzymes. Plant Physiol. 30:78-80.

Schönherr, J. and M. Riederer. 1986. Plant cuticles sorb lipophilic compounds during enzymatic isolation. Plant Cell Environ. 9:459-466.

Shirazi, A. and A.C. Cameron. 1993. Measuring transpiration rates of tomato and other detached fruit. HortScience 28:1035-1038.

Wexler,A. 1995. Constant humidity solutions, p. 1523. In: D.R. Lide (ed.). Handbook of chemistry and physics. CRC Press, Boca Raton, Fla.

Yamada, Y., S.H. Wittwer, and M.J. Bukovac. 1964. Penetration of ions through isolated cuticles. Plant Physiol. 39:28-32. 